\title{
SELF-INCOMPATIBILITY IN ESCHSCHOLZIA CALIFORNICA
}

\author{
G. M. WRIGHT \\ Crop Research Division, DSIR, Christchurch, New Zealand
}

Received 19.iv.79

IN reporting their studies of Papaver rhoeas, Lawrence et al. (1978) discussed a degree of uncertainty that must apply to descriptions of gametophytic incompatibility systems with single-locus control. This follows the discovery (Lundqvist et al., 1973; Østerbye, 1975) of a system with at least three loci in Ranunculus acris, a member of the Ranunculaceae. Referring to evidence that the order Papaverales is derived from the order Ranunculales, Lawrence et al. (1978) suggested that control of self-incompatibility and site of inhibition of pollen growth should be studied in other members of the Papaveraceae. They have overlooked the demonstration of gametophytic control in Papaver nudicaule, the Iceland poppy (Fabergé, 1942).

In Eschscholzia, another genus of the Papaveraceae, the California poppy E. californica Cham. has generally shown a high level of self-sterility. Beatty (1936) found that inhibition of pollen tube growth in this species occurred in the stigma. The orthodox site of inhibition for the one-locus gametophytic (Nicotiana) system which the present results support is the style, but Papaver species have no style. Beatty's result supports the prediction of Lawrence et al. (1978) that stigmatic inhibition in poppies is likely to turn out to be a familial, rather than a generic characteristic. However, Brewbaker (1957) reported that the site of inhibition in Papaver nudicaule is the ovary.

Two California poppy plants of a cultivated strain were grown together in apparent isolation from other plants; neither set seed when the other was not flowering. Reciprocal crosses were made without emasculation. Germination of the seed was high, 10 plants of each of the reciprocal crosses were potted, and the 20 plants were kept in separate glasshouse cells. All plants began flowering within 4 days, 8 weeks after sowing. Crosses were made over two successive summers, but two plants died before many crosses had been made. Six plants were crossed with the surviving parent plant, and all six crosses were successful.

The results obtained by intercrossing 18 plants are shown in fig. 1. As in figs. 6 and 7 of Lawrence et al. (1978) the plants fall into four groups, arbitrarily labelled from $A$ to $D$. Chi-square for the test of equality of the group sizes $(7,4,4,3)$ is the same as for the $(6,6,3,3)$ of fig. 7 (loc. cit.), a non-significant 2.00 with 3 degrees of freedom. Crosses between plants within each group were unsuccessful. Crosses between plants placed in different groups were generally successful; all those attempted twice were successful at least once, but five of those attempted once only did not succeed. Several crosses were made successfully in both directions, and there was no evidence of reciprocal differences in compatibility. The six plants crossed with one of the parents, nos. $1,4,8,10,18$ and 19, covered all four compatibility groups.

The simplest interpretation is that the two parent plants differed in both $S$-alleles at a single incompatibility locus. The parental genotypes being $S_{1} S_{2}$ 
and $S_{3} S_{4}$, the four groups of plants established are, in unknown order, $S_{1} S_{3}$, $S_{1} S_{4}, S_{2} S_{3}$ and $S_{2} S_{4}$, and all the plants would be compatible with both parents.

Of the 18 plants that flowered for several months in the glasshouses, four produced several small pods in the cooler months without hand-crossing, with a small number of viable seeds assumed to be selfs. The maximum was 25 seeds per pod compared with the normal 100 or more produced by crossing, and most of the pods had less than five seeds (see legend to fig. 1).

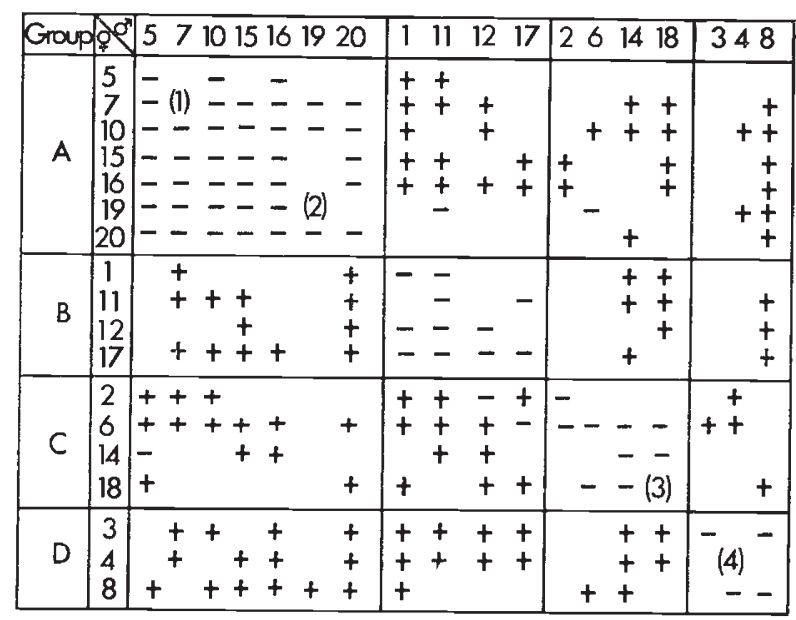

FIG. 1.-The crosses attempted. Entries in the top and left-hand margins of the table are plant numbers; in the table a + indicates a successful cross, a - an unsuccessful cross. Production of seed by presumed self-fertilisation: (1) plant 7 had 3 pods, with 5,7 , and 25 seeds, (2) 10 pods gave a total of 34 seeds, (3) 1 pod, 1 seed, (4) 1 pod, 2 seeds.

The results do not prove that only one locus is significant in the control of self-incompatibility in $E$. californica (cf. Lawrence et al., 1978), but they are fully consistent with this interpretation. The partial break-down of selfsterility shown by a few plants at low temperatures was presumably genetically influenced, but neither this nor the occurrence in other material of completely self-fertile plants has been studied further.

Darwin (1876) and earlier workers he quoted, and Douwes (1943), reported fairly high levels of self-fertility in their stocks of $E$. californica, whereas Stout (1920) and Beatty (1936) found most of their plants were self-sterile. Darwin also established an effect of temperature, as one of the strains used in his study of inbreeding had come to him from Brazil, where it had been completely self-sterile.

\section{REFERENGES}

BEATty, A. v. 1936. Genetic studies on the California poppy. F. Heredity, 27, 331-338. Brewbaker, J. L. 1957. Pollen cytology and self-incompatibility systems in plants. $\mathcal{J}$. Heredity, 48, 271-277.

Darwin, C. 1876. The Effects of Cross and Self Fertilisation in the Vegetable Kingdom. John Murray, London.

Douwes, H. 1943. Een genetisch-chemisch onderzoek van Eschscholtzia Californica Cham. Genetica, 23, 353-464. 
FABERGÉ, A. G. 1942. Genetics of the Scapiflora section of Papaver. I. The garden Iceland poppy. 7. Genetics, 44, 169-193.

LAWRENCE, M. J., AFZAL, M., AND KENRIGK, J. 1978. The genetical control of selfincompatibility in Papaver rhoeas. Heredity, 40, 239-253.

LUNDQVist, A., øSTERBYe, U., LARSEN, K., AND LINDE-LAURSEN, I. 1973. Complex selfincompatibility systems in Ranunculus acris L. and Beta vulgaris L. Hereditas, 74, 161-168. øSTERBYE, U. 1975. Self-incompatibility in Ranunculus acris L. I. Genetic interpretation and evolutionary aspects. Hereditas, $80,91-112$.

stout, A. B. 1920. Further experimental studies on self-incompatibility in hermaphrodite plants. 7. Genetics, 9, 85-129. 